\title{
Association Between Physiotherapy Outcome Measures and the Functional Independence Measure: A Retrospective Analysis
}

\author{
Maren Jones, MPH, BS, Lyndel Hewitt, PhD, BAppSc, Philippa King, BSc, Rhiannon Thorn, BPT, \\ Edward Davidson, BAppSc, and Tiana-Lee Elphick, MSB, BS
}

Objective: To assess the association between change scores in the Functional Independence Measure (FIM) with evaluative measures used in physiotherapy to objectively show that use of the FIM in isolation is limited.

Design: Retrospective observational study.

Setting: Five rehabilitation inpatient wards from 1 public local health district in NSW Australia.

Participants: Patient data over a 5-year time frame (2015 to 2019) were reviewed $(\mathrm{N}=2378)$. The patient data from the 3 most prevalent impairment groups (Australasian Rehabilitation Outcome Centre classification) were identified for inclusion in this study: Reconditioning $(\mathrm{n}=742$, mean age 76.88 years); Orthopedic Fracture ( $n=585$, mean age 77.46 years); and Orthopedic Replacement ( $n=377$, mean age 73.84 years).

Measurements: The difference between the admission and discharge scores were calculated for each measure.
Kruskal-Wallis and $\chi^{2}$ tests were used to analyze the data.

Results: Pearson correlation ( $r$ ) coefficients between FIM Motor change to the de Morton's Mobility Index (DEMMI) change was $r=0.396$, FIM Motor change to the Timed Up and Go (TUG) change was $r=-0.217$, and the FIM Motor change to the Ten Meter Walk Test (10MWT) change was .194.

Conclusion: The FIM Motor change scores showed a weak positive association to the DEMMI change and no association to the TUG and 10MWT change, demonstrating that the outcome measures do not measure the same attributes. To review rehabilitation effectiveness from a management perspective, it is recommended that all measures are reviewed to assess the burden of care, functional mobility, and dynamic balance.

Keywords: physiotherapy; rehabilitation; clinical outcome measures.
$\mathrm{P}$ atients receive interdisciplinary inpatient rehabilitation treatment after they have sustained a lower limb fracture, a lower limb joint replacement, or have generalized deconditioning (muscle wasting and disuse atrophy) following hospitalization for surgery or illness. The degree of a patient's impairment or loss of functional capacity, as well as their ability to manage at home safely, is assessed using standardized outcome measures during their recovery and rehabilitation., ${ }^{1,2}$

Physiotherapists routinely use validated outcome measures to assess patient progress and to measure goal attainment through assessment of functional independence, dynamic balance performance, and ambulatory ability. These objective assessments provide clinicians with information about the effectiveness of the rehabilitation program, as well as the patient's ability to manage in their home environment, to determine the need for assistive devices, level of caregiver support, future level of autonomy, and strategies for falls prevention. ${ }^{3-7}$

There is a view among service providers that rehabilitation decisions can be based on a singular measure of function known as the Functional Independence Measure (FIM). This is an understandable position because not only is the FIM an internationally recognized, valid, and reliable tool, but, as a singular measure, it also means

From Illawarra Shoalhaven Local Health District, New South Wales, Australia (Maren Jones, Dr. Hewitt, Philippa King, Rhiannon Thorn, Edward Davidson, and Tiana-Lee Elphick), and Illawarra Health and Medical Research Institute, University of Wollongong, Wollongong, New South Wales, Australia (Dr. Hewitt). 
measurement consistency across rehabilitation sites is more likely. However, rehabilitation is complex, and it is risky to base decisions on a single measure, which might not capture the results of rehabilitation treatment ingredients on individual patient targets. , $^{8,9}$

The patient's progress is objectively assessed using functional outcome measures such as the FIM. Other measures used typically in our service include the de Morton's Mobility Index (DEMMI), Timed Up and Go (TUG), and the Ten Meter Walk Test (10MWT), which measure patient mobility, balance during directional changes, and walking ability, respectively. Additional measures include patient progression to a less supportive level of assistance (ie, number of persons required to assist or level of supervision) or the selection of a walking aid (eg, forearm support frame, crutches). This progression-or lack thereof-assists in decision-making regarding the individual's future once they are discharged from rehabilitation. Such considerations would include the need to modify the home environment, selection of assistive devices, community access (walking indoors, outdoors, and shopping), personal care needs, and age-appropriate care facility recommendations (ie, level of care). The use of outcome measures also indicates the need for further referrals to other care providers upon discharge from the rehabilitation facility.

There is widespread support in the literature for the use of the FIM, DEMMI, TUG, and 1OMWT in rehabilitation population groups. For example, DEMMI has been validated in hip fracture patients during rehabilitation, ${ }^{10}$ as well as among older people hospitalized for medical illness. ${ }^{11-13}$ It has also been shown to be a predictor of discharge destination for patients living with frailty in geriatric rehabilitation settings, ${ }^{14}$ and to have moderate predictive validity for functional independence after 4 weeks of rehabilitation. ${ }^{15}$ Similarly, TUG has been validated for use among hospitalized and community-dwelling individuals, ${ }^{16-18}$ and for patients after joint arthroplasty ${ }^{19,20}$ or hip fracture. ${ }^{21}$ It has also been shown to be an indicator of fall risk, ${ }^{22-24}$ as well as a predictor of fracture incidence. ${ }^{25}$ Furthermore, TUG has been identified as an indicator of a patient's ability to walk in the community without the need for a walking device. ${ }^{26}$ It has also been shown to be an early identifier of patients in need of rehabilitation. ${ }^{27}$ Normative values for
TUG have been reported, and the association with gait time established. ${ }^{28}$

Gait speed has been shown to predict adverse outcomes in community-dwelling older people..9 In fact, the 1OMWT has been established as a powerful tool to benchmark rehabilitation recovery after a medical event. ${ }^{30}$ Results of the test relate to overall quality of walking, health status, morbidity, and the rate of mortality. ${ }^{31-33}$ Meaningful improvement, minimum detectable change (0.19-0.34 $\mathrm{m} / \mathrm{s}$ ), and responsiveness in common physical performance in older adults has been reported. ${ }^{26,34,36}$

Structural and functional impairment has been used to define rehabilitation classes by the Australasian Rehabilitation Outcome Centre (AROC) in the Australian National Sub-Acute and Non-Acute Patient Classification (AN-SNAP) Version 4..$^{37-43}$ Variables used for grouping are age, care type, function, and impairment for rehabilitation. FIM was developed in order to assess patients' outcomes after inpatient multidisciplinary care, and is an internationally accepted measure of functioning. ${ }^{44}$ It is a holistic outcome measure, which can be used to determine the patient's level of disability and burden of care, and is widely used in both public and private inpatient rehabilitation settings. Each patient classification is reported separately within the case mix structure. ${ }^{45}$ Inpatient rehabilitation centers are evaluated and compared by the $\mathrm{AROC},{ }^{46}$ with an emphasis on length of stay and the FIM change. The most successful centers demonstrate shorter length of stay and greater FIM improvement. Although the FIM is a valuable measure, it does not provide a complete picture of the individual patient's rehabilitation gain: ie, the specific attributes of patients' mobility, walking ability, or balance during directional changes.

A large-scale analysis of the association between the holistic disability measure of the FIM and the more mobility- and ambulation-focused physiotherapy outcomes has not been documented.

The well-documented DEMMI accumulates points for the patient's mobility in a similar fashion to the FIM, but with more mobility detail. These 2 outcome measures allow for the full range of patients, from the very dependent up to and including the independently ambulant patients. The DEMMI may show a positive relationship to the FIM, yet the association is unknown. The association of the TUG to the 
10MWT has been established ${ }^{28}$; however, their relationship to the FIM is unknown.

Current practice in the participating public health inpatient rehabilitation wards is to use the DEMMI, TUG, 1OMWT, and FIM to ensure physiotherapy and allow the wider multidisciplinary team to more effectively evaluate patient mobility outcomes. The 3 most frequent patient groups identified within the current patient population are expected to present clinical differences and will be analyzed for comparison. If an association is found between the outcome measures in question, clinical efficiency could be improved.

The aim of the current study is to assess the association between change scores in the FIM with evaluative measures of outcomes typically used in physiotherapy to objectively show that use of the FIM in isolation is limited in our population of patients.

\section{Methods}

\section{Study design and setting}

This retrospective descriptive observational study complied with the STROBE-RECORD guidance and checklist (available at mdedge.com/jcomjournal) and analyzed the routinely collected data from rehabilitation patients who were admitted to 5 different rehabilitation wards in 4 different public hospitals from 1 regional local health district (20-24 beds per ward) from 2015 to 2019. As this study conducted secondary analyses using existing de-identified data from a public health facility and did not involve interaction with any human subjects, ethical approval was not required. ${ }^{46}$ Approval to conduct this study was granted by the health district's institutional review committee, as per the National Statement on Ethical Conduct in Human Research 2015.

\section{Participants}

Patient data over a 5-year time frame were reviewed $(\mathrm{N}=2378)$. The patient data from the 3 most prevalent impairment groups were identified for inclusion in this study: reconditioning, orthopedic fracture, and orthopedic replacement. (See Table 1 for the specific AN-SNAP impairment groups used in this study.)

Patient data from the less-frequent impairment groups were excluded ( $n=673,28.19 \%)$, including stroke $(n=343)$,

\begin{tabular}{|c|c|}
\hline $\begin{array}{l}\text { Impairment } \\
\text { group }^{48}\end{array}$ & $\begin{array}{l}\text { Australian National Sub-Acute and Non- } \\
\text { Admitted Patient Classification }^{46}\end{array}$ \\
\hline \multirow[t]{3}{*}{ Reconditioning } & - Reconditioning following illness \\
\hline & - Reconditioning following surgery \\
\hline & - Reconditioning following cancer rehabilitation \\
\hline \multirow{8}{*}{$\begin{array}{l}\text { Orthopedic } \\
\text { fracture }\end{array}$} & - Ortho fracture hip bilateral \\
\hline & - Ortho fracture knee \\
\hline & - Ortho fracture leg ankle foot \\
\hline & - Ortho fracture multiple sites \\
\hline & - Ortho fracture pelvis \\
\hline & - Ortho fracture shaft femur \\
\hline & - Ortho fracture other \\
\hline & - Ortho other surgery \\
\hline \multirow{4}{*}{$\begin{array}{l}\text { Orthopedic } \\
\text { replacement }\end{array}$} & - Ortho bilateral knee replacement \\
\hline & - Ortho unilateral knee replacement \\
\hline & - Ortho bilateral hip replacement \\
\hline & - Ortho unilateral hip replacement \\
\hline
\end{tabular}
AROC, Australasian Rehabilitation Outcome Centre.

brain dysfunction $(n=45)$, amputation of $\operatorname{limb}(n=45)$, spinal cord dysfunction $(n=36)$, neurological dysfunction $(n=34)$, cardiac $(n=24)$, and others $(n=25)$ who may have benefitted from other outcome measures due to their medical condition. Ten patient data sets were excluded for missing discharge outcome measure data, from when the patient became ill and returned to acute services or was discharged at short notice. To be included in the study, both the admission and discharge scores from the FIM and the admission and discharge scores from at least 1 of the physiotherapy outcome measures were required for each patient $(n=1704,71.39 \%)$ : Reconditioning $(n=742)$, Orthopedic Fracture $(n=585)$, and Orthopedic Replacement $(n=377)$. Information regarding the type of walking aid and the amount of assistance required for safe ambulation was also recorded. These items were included in the study's descriptive analysis. Only $1.7 \%$ of these descriptors were missing.

\section{Outcome measures}

DEMMI tasks of bed mobility, sitting balance, transfers, walking, and balance were scored with an assigned 
Table 2. Patient Demographic Information ( $N=1704)$

\begin{tabular}{|c|c|c|c|}
\hline Units & $\begin{array}{l}\text { Reconditioning patients } \\
(\mathrm{n}=742)\end{array}$ & $\begin{array}{l}\text { Orthopedic fracture } \\
\text { patients }(n=585)\end{array}$ & $\begin{array}{l}\text { Orthopedic replacement } \\
\text { patients }(n=377)\end{array}$ \\
\hline \multicolumn{4}{|l|}{ Site, n (\%) } \\
\hline Site 1 & $145(19.54)$ & $139(23.76)$ & 76 (20.16) \\
\hline Site 2 & $170(22.91)$ & $147(25.13)$ & $84(22.28)$ \\
\hline Site 3 & $170(22.91)$ & $140(23.93)$ & $103(27.32)$ \\
\hline Site 4 & $159(21.43)$ & $101(17.26)$ & $82(21.75)$ \\
\hline Site 5 & $98(13.21)$ & $58(9.91)$ & $32(8.49)$ \\
\hline Mean (SD) length of stay, $d$ & 23.87 (22.37) & $26.46(16.44)$ & 18.03 (13.62) \\
\hline \multicolumn{4}{|l|}{ Age, y } \\
\hline Mean (SD) & $76.88(11.58)$ & $77.46(11.60)$ & $73.84(9.70)$ \\
\hline Range, y & $48-101$ & $45-93$ & $29-98$ \\
\hline \multicolumn{4}{|l|}{ Discharge destination, $\mathrm{n}(\%)^{\mathrm{a}}$} \\
\hline Hospital & $24(3.25)$ & $12(2.07)$ & $2(0.54)$ \\
\hline Home & $645(87.40)$ & $502(86.40)$ & $356(97.00)$ \\
\hline High-level care & $40(5.42)$ & $34(5.85)$ & $4(1.09)$ \\
\hline Low-level care & $26(3.52)$ & $25(4.30)$ & $2(0.54)$ \\
\hline Family & $3(0.41)$ & $8(1.38)$ & $3(0.82)$ \\
\hline \multicolumn{4}{|l|}{ Aid improvement, $\mathrm{n}(\%)^{\mathrm{b}}$} \\
\hline No & $426(58.20)$ & $176(30.66)$ & $91(24.73)$ \\
\hline Yes & $306(41.80)$ & $398(69.34)$ & $277(75.27)$ \\
\hline \multicolumn{4}{|l|}{ Assist improvement, $\mathrm{n}(\%)^{c}$} \\
\hline No & $193(26.26)$ & $103(17.85)$ & $94(25.20)$ \\
\hline Yes & 542 (73.74) & 474 (82.15) & $279(74.80)$ \\
\hline \multicolumn{4}{|c|}{$\begin{array}{l}\text { Data missing for } 4 \text { reconditioning patients, } 4 \text { orthopedic fracture patients, and } 10 \text { orthopedic replacement patients. } \\
\text { 'Data missing for } 10 \text { reconditioning patients, } 11 \text { orthopedic fracture patients, and } 9 \text { orthopedic replacement patients. } \\
\text { 'Data missing for } 7 \text { reconditioning patients, } 8 \text { orthopedic fracture patients, and } 4 \text { orthopedic replacement patients. }\end{array}$} \\
\hline
\end{tabular}

value according to the patient's performance. This was then tallied and the results scaled, to provide an overall score out of 100 available points. The total score from admission and discharge was then compared. Improvement (change) was identified by the increase in scores.

The TUG assesses a patient's dynamic balance performance. ${ }^{47}$ The number of seconds it took the patient to complete the procedure was recorded at admission and discharge. Improvement (change) was identified by the reduction in time taken at discharge from the admission score.

The 10MWT measures the unidirectional walking speed of a person over 10 meters and is recorded in sec- onds and reported in meters per second. Improvement (change) was identified by the reduction in the time taken to increase walking speed.

Concurrent to the physiotherapy measures were the FIM scores, recorded by the accredited nursing staff from each rehabilitation ward. Improvement is demonstrated by the accumulation of points on the ordinal scale of the FIM Total, including mobility, dressing, bladder and bowel care, cognition, and social interaction, and is represented as a score between 18 and 126 . The FIM Motor category is reported as a score between 13 and 91.

The 2 data sets were matched by unique identifier and admission dates, then de-identified for analysis. 


\section{Statistical analysis}

Patient demographic information was analyzed using descriptive statistics (mean, SD, frequencies, percentages) for each impairment group (orthopedic fracture, orthopedic replacement, reconditioning). Differences in continuous demographic variables for each impairment group were assessed using Kruskal-Wallis tests and $\chi^{2}$ tests for categorical variables. Functional outcome scores were compared at admission, discharge, and change between the impairment groups. Association of the functional outcome change scores was determined with the Pearson correlation coefficient $(r)$ between the FIM and the DEMMI, TUG, and 10MWT. Graphs were plotted for each of these (Figure available online at mdedge.com/ jcomjournal). A strong, moderate, and weak association was described as $>0.6,>0.4$, and $>0.2$, respectively. ${ }^{46}$ Statistical significance was set at $P<.05$. Analyses were conducted using Stata (StataCorp LLC, USA).

\section{Results}

The patient descriptive data (site from which data were collected, admission length of stay, age at admission, discharge destination, walk aid improvement, and walk assistance improvement) from the 3 impairment groups are reported in Table 2. The functional outcomes for DEMMI, TUG, 10MWT, FIM Motor, FIM Total at admission, discharge, and the change scores are presented in Table 3.

Orthopedic fracture patients had the greatest improvement in their functional outcomes, with a DEMMI improvement of 18 points, TUG score change of 23.49 seconds (s), 10MWT change of 0.30 meters/second $(\mathrm{m} / \mathrm{s})$, FIM Motor change of 20.62, and a FIM Total change of 21.9 points. The outcome measures exceeded the minimum detectable change as reported in the literature for DEMMI (8.8 points $\left.{ }^{48}\right)$, TUG $\left(2.08 \mathrm{~s}^{26}\right)$, walking speed $0.19 \mathrm{~m} / \mathrm{s}^{26}$, and FIM Motor (14.6 points $\left.{ }^{49}\right)$.

\section{Association of functional outcomes (change scores)}

There was a significant weak positive correlation between DEMMI change score and both the FIM Motor ( $r=0.396)$ and FIM Total change scores $(r=0.373)$. When viewing the specific items within the FIM Motor labelled FIM Walk change, FIM MobilityBedChair change, and FIM stairs change, $r$ values were $0.100,0.379$, and 0.126 , respectively.
In addition, there was a weak negative correlation between TUG change scores and both FIM Motor $(r=-0.217)$ and FIM Total change scores $(r=-0.207)$. There was a very weak positive correlation between 10MWT $(\mathrm{m} / \mathrm{s})$ change scores and both FIM Motor ( $r=0.194)$ and FIM Total change scores $(r=0.187)$ (Table 4, Figure). There was a moderate correlation between 10MWT change (s) and TUG change (s) $(r=0.72, P<.001)$.

\section{Discussion}

The purpose of this study was to ascertain the association between the DEMMI, TUG, 1OMWT, and FIM measures using retrospective data collected from 5 public hospital inpatient rehabilitation wards. The results of this retrospective analysis demonstrate that a variety of objective outcome measures are required for the multidisciplinary team to accurately measure a patient's functional improvement during their inpatient rehabilitation stay. No single outcome measure in this study fully reported all mobility attributes, and we note the risk of basing decisions on a single measure evaluating rehabilitation outcomes. Although the internationally used FIM has a strong place in rehabilitation reporting and benchmarking, it does not predict change nor provide a proxy for the patient's whole-body motor control as they extend their mobility, dynamic balance, and ambulatory ability. Multiple objective outcome measures should therefore be required to evaluate the patient's progress and functional performance toward discharge planning.

The FIM is a measure of disability or care needs, incorporating cognitive, social, and physical components of disability. It is a valid, holistic measure of an individual's functional ability at a given time. Rehabilitation sites internationally utilize this assessment tool to evaluate a patient's progress and the efficacy of intervention. The strength of this measure is its widespread use and the inclusion of the personal activities of daily living to provide an overall evaluation encompassing all aspects of a person's ability to function independently. However, as our study results suggest, patient improvement measured by the FIM Motor components were not correlated to other widely used physiotherapy measures of ambulation and balance, such as the 10MWT or TUG. This is perhaps largely because the FIM Motor components only consider the level of assistance (eg, physical assistance, assistive 
Table 3. Functional Outcomes ( $\mathrm{N}=1704)$

\begin{tabular}{|c|c|c|c|c|c|}
\hline & Unit & $\begin{array}{l}\text { Reconditioning } \\
\text { patients }(n=742)\end{array}$ & $\begin{array}{l}\text { Orthopedic fracture } \\
\text { patients }(n=585)\end{array}$ & $\begin{array}{l}\text { Orthopedic } \\
\text { replacement } \\
\text { patients }(n=377)\end{array}$ & $P$ value \\
\hline \multicolumn{6}{|c|}{ DEMMI $(n=979)$} \\
\hline Mean (SD) & \multirow{7}{*}{$\begin{array}{l}\text { Out of } 100 \\
\text { points }\end{array}$} & & & & \\
\hline Admission & & 35.59 (14.88) & $31.00(11.72)$ & $34.63(12.01)$ & $<.001$ \\
\hline Range & & 0.00-100.00 & $0.00-85.00$ & $2.00-67.00$ & \\
\hline Discharge & & $50.49(15.38)$ & $48.93(11.94)$ & 52.39 (10.18) & .004 \\
\hline Range & & $8.00-100.00$ & $0.00-100.00$ & $27.00-100.00$ & \\
\hline Change & & $14.91(11.81)$ & $18.01(11.47)$ & $18.03(11.14)$ & $<.001$ \\
\hline Range & & $-12.00-67.00$ & $-39.00-56.00$ & $-5.00-54.00$ & \\
\hline \multicolumn{6}{|c|}{ TUG $(n=1180)$} \\
\hline Mean (SD) & \multirow[t]{7}{*}{ Seconds } & & & & \\
\hline Admission & & $33.72(20.39)$ & $45.93(28.09)$ & $42.40(23.95)$ & $<.001$ \\
\hline Range & & 7.6-190.00 & $8.81-230.00$ & $13.00-144.00$ & \\
\hline Discharge & & 23.58 (14.94) & $23.45(10.20)$ & 22.70 (11.32) & .008 \\
\hline Range & & $6.20-120.00$ & 7.53-95.00 & $8.50-102.00$ & \\
\hline Change & & $-11.23(16.41)$ & $-23.49(26.71)$ & $-21.03(21.97)$ & $<.001$ \\
\hline Range & & $-162.6-49.53$ & $-206.69-31.00$ & $-126.32-26.62$ & \\
\hline \multicolumn{6}{|c|}{ 10MWT $(n=1476)$} \\
\hline Mean (SD) & \multirow{7}{*}{$\begin{array}{l}\text { Meters per } \\
\text { second }\end{array}$} & & & & \\
\hline Admission & & $0.52(0.22)$ & $0.38(0.19)$ & $0.39(0.18)$ & $<.001$ \\
\hline Range & & $0.05-1.25$ & $0.04-1.00$ & $0.05-0.95$ & \\
\hline Discharge & & $0.69(0.28)$ & $0.66(0.24)$ & $0.64(0.22)$ & .052 \\
\hline Range & & $0.09-1.61$ & $0.09-1.59$ & $0.10-1.33$ & \\
\hline Change & & $0.20(0.21)$ & $0.30(0.24)$ & $0.27(0.21)$ & $<.001$ \\
\hline Range & & $-0.37-0.98$ & $-0.33-1.35$ & $-0.31-0.89$ & \\
\hline \multicolumn{6}{|c|}{ FIM Motor $(n=1704)$} \\
\hline Mean (SD) & \multirow{7}{*}{$\begin{array}{l}13 \text { to } 91 \\
\text { points }\end{array}$} & & & & \\
\hline Admission & & 53.79 (15.48) & $51.91(13.76)$ & $58.78(13.28)$ & $<.001$ \\
\hline Range & & $13.00-89.00$ & $15.00-85.00$ & $13.00-91.00$ & \\
\hline Discharge & & 71.27 (15.14) & 72.52 (13.72) & $78.52(9.90)$ & $<.001$ \\
\hline Range & & $13.00-91.00$ & $15.00-91.00$ & $28.00-91.00$ & \\
\hline Change & & 17.45 (12.83) & 20.62 (13.48) & 19.75 (11.94) & $<.001$ \\
\hline Range & & $-63.00-67.00$ & $-24.00-61.00$ & $-13.00-69.00$ & \\
\hline \multicolumn{6}{|c|}{ FIM Total $(n=1704)$} \\
\hline Mean (SD) & \multirow{7}{*}{$\begin{array}{l}19 \text { to } 126 \\
\text { points }\end{array}$} & & & & \\
\hline Admission & & 81.57 (19.52) & 80.15 (17.31) & 89.35 (16.49) & $<.001$ \\
\hline Range & & $0.00-124$ & $21.00-120.00$ & $27.00-126.00$ & \\
\hline Discharge & & 99.86 (19.51) & $102.03(17.44)$ & 110.29 (12.41) & $<.001$ \\
\hline Range & & $0.00-126.00$ & $21.00-126.00$ & $52.00-126.00$ & \\
\hline Change & & $18.29(14.23)$ & 21.88 (14.64) & 20.94 (12.99) & $<.001$ \\
\hline Range & & $-80.00-71.00$ & $-34.00-66.00$ & $-13.00-89.00$ & \\
\hline
\end{tabular}


Table 4. Correlation of Functional Outcomes

\begin{tabular}{llll}
\hline & $\begin{array}{l}\text { Correlation with } \\
\text { DEMMI change (Pearson } \boldsymbol{r} \text { ) }\end{array}$ & $\begin{array}{l}\text { Correlation with } \\
\text { TUG change (Pearson } \boldsymbol{r} \text { ) }\end{array}$ & $\begin{array}{l}\text { Correlation with } \\
\text { 10MWT change (Pearson } \boldsymbol{r} \text { ) }\end{array}$ \\
\hline FIM Motor change & 0.396 & -0.217 & 0.194 \\
\hline FIM Total change & 0.373 & -0.207 & 0.187 \\
\hline FIM Walk change & 0.100 & -0.02 & 0.188 \\
\hline FIM MobilityBedChair change & 0.379 & -0.223 & 0.192 \\
\hline FIM Stairs change & 0.126 & 0.05 & 0.073 \\
\hline
\end{tabular}

DEMMI, de Morton's Mobility Index; FIM, Functional Independence Measure; TUG, Timed Up and Go; 10MWT, Ten Meter Walk Test.

device, independence) and do not consider assessment of balance and gait ability as assessed in the 10MWT and TUG. The 1OMWT and TUG provide assessment of velocity and dynamic balance during walking, which have been shown to predict an individual's risk of falling. ${ }^{22,23}$ This is a pertinent issue in the rehabilitation and geriatric population. ${ }^{29}$ Furthermore, the use of the FIM as a benchmarking tool to compare facility efficiency may not provide a complete assessment of all outcomes achieved on the inpatient rehabilitation ward, such as reduced falls risk or improved ambulatory ability and balance.

Of the objective measures evaluated in our paper, the DEMMI assessment has the most similar components to those of the FIM Motor. It includes evaluating independence with bed mobility, standing up, and ambulation. In addition, the DEMMI includes assessment of both static and dynamic balance. As a result of these commonalities, there was only a weak positive correlation between the change in DEMMI and the change in FIM Motor and FIM Total. However, this correlation is not statistically significant. Therefore, the FIM is not recommended as a replacement of the DEMMI, nor can one be used to predict the other.

It has previously been confirmed that there is a significant positive correlation between the 10MWT and the TUG. ${ }^{27}$ This retrospective analysis has also supported these findings. This is possibly due to the similarity in the assessments, as they both incorporate ambulation ability and dynamic movement.

Each of the 4 outcome measures assess different yet vital aspects of an individual's functional mobility and ambulation ability during their subacute rehabilitation journey. The diversity of patient age, functional impairment, and mobility level needs a range of outcomes to provide baselines, targets, and goal attainment for discharge home.

Consistent with the AROC AN-SNAP reporting of Length of Stay and FIM change separated into the weighted impairment groups, the data analysis of this study demonstrated significant differences between the Reconditioning, Orthopedic Fracture, and Orthopedic Replacement patient data. Tables 2 and 3 describe the differences between the groups. The fracture population in this study improved the most across each outcome measure. In contrast, the reconditioning population showed the least improvement. This may be expected due to the pathophysiological differences between the groups. Furthermore, for the elderly who sustain fractures because of a fall, rehabilitation will be required to address not only the presenting injury but also the premorbid falls risk factors which may include polypharmacy or impaired balance.

Any conclusions drawn from the findings of this study need to take into consideration that it has focused on patients from 1 local health district and therefore may not be generalizable to a wider national or international context. As this study was a retrospective study, controlling for data collection quality, measurement bias due to nonblinding and missing data is a limitation. However, clinicians regularly completed these outcome assessments and recorded this information as part of their standard care practices within this health district. There may have been slight differences in definitions of practice between the 5 rehabilitation sites. To ensure reliability, each individual site's protocols for the FIM, DEMMI, TUG, and 10MWT were reviewed and confirmed to be consistent. 
It is important, too, to consider the ceiling effect for the FIM scores. For patients requiring a walking aid well after discharge, the highest level of independence from the walking aid will not be achieved. It is acknowledged that the floor effect of the 10MWT and TUG may also influence the outcomes of this study. In addition, data were not collected on preadmission functional measures to enable further evaluation of the population groups. The proportion of variance in change from admission to discharge for TUG and 10MWT to FIM was less than 5\%, so the correlation interpretation from this type of scaling is limited. Further research into outcome measures for inpatient rehabilitation in respect to variables such as patient age, length of stay, discharge destination, and efficacy of intervention is warranted.

\section{Conclusion}

The FIM Motor change scores showed a weak positive association to the DEMMI change, and no association to the TUG and 10MWT change, demonstrating that the outcome measures do not measure the same attributes. Thorough reporting of clinical outcomes is much more meaningful to assess and guide the physiotherapy component of rehabilitation. To review rehabilitation effectiveness from a management perspective, it is recommended that all measures are reviewed to assess the burden of care, mobility, functional capacity, and dynamic balance.

Acknowledgements: The authors thank Anne Smith, MSHLM, BAppSc, Head of the Physiotherapy Department, and the physiotherapists and allied health assistants who have contributed to the collection of this valuable data over several years. They also thank Lina Baytieh, MS, BS, from Research Central, Illawarra Shoalhaven Local Health District, for her assistance with the analysis.

Corresponding author: Maren Jones, MPH, BS, Physiotherapy Department, Port Kembla Hospital, Illawarra Shoalhaven Local Health District, Warrawong, New South Wales, 2505 Australia; maren.jones@health.nsw.gov.au.

Financial disclosures: None.

doi:10.12788/jcom.0069

\section{References}

1. Centers for Disease Control and Prevention. Disability and health overview. Impairments, activity limitations and participation restrictions. September 16, 2020. https://www.cdc.gov/ncbddd/disabilityandhealth/disability.html

2. The Royal Australasian College of Physicians. Australasian Faculty of Rehabilitation Medicine. Standards for the Provision of Inpatient Adult Rehabilitation Medicine Services in Public and Private Hospitals. February 2019:7-9. https://www.racp.edu.au/ docs/default-source/advocacy-library/afrm-standards-for-theprovision-of-inpatient-adult-rehabilitation-medicine-servicesin-public-and-private-hospitals.pdf?sfvrsn=4690171a_4

3. NSW Agency for Clinical Innovation. NSW rehabilitation model of care. June 1, 2015. https://aci.health.nsw.gov.au/resources/ rehabilitation/rehabilitation-model-of-care/rehabilitation-moc

4. The State of Queensland (Queensland Health). Clinical task instructions. June 22, 2021. https://www.health.qld.gov.au/ahwac/html/ clintaskinstructions

5. Panel on Prevention of Falls in Older Persons, American Geriatrics Society and British Geriatrics Society. Summary of the updated American Geriatrics Society/British Geriatrics Society clinical practice guideline for prevention of falls in older persons. J Am Geriatr Soc. 2011;59(1):148-157. doi:10.1111/j.1532-5415.2010.03234.x

6. Suwannarat P, Kaewsanmung $\mathrm{S}$, Thaweewannakij T, Amatachaya $\mathrm{S}$. The use of functional performance tests by primary health-care providers to determine walking ability with and without a walking device in community-dwelling elderly. Physiother Theory Pract. 2021;37(1):64-72. doi:10.1080/09593985.2019.1606372

7. Lee K-J, Um S-H, Kim Y-H. Postoperative rehabilitation after hip fracture: a literature review. Hip Pelvis. 2020;32(3):125-131. do: 10.5371/hp.2020.32.3.125

8. Wade DT, Smeets RJEM, Verbunt JA. Research in rehabilitation medicine: methodological challenges. J Clin Epidemiol. 2010;63(7):699-704. doi:10.1016/j.clinepi.2009.07.010

9. Wade DT. Outcome measures for clinical rehabilitation trials: impairment, function, quality of life, or value? Am J Phys Med Rehabil. 2003;82(suppl 10):S26-S31. doi:10.1097/01. PHM.0000086996.89383.A1

10. de Morton NA, Harding KE, Taylor NF, Harrison G. Validity of the de Morton NA Mobility Index (DEMMI) for measuring the mobility of patients with hip fracture during rehabilitation. Disabil Rehabil. 2013;35(4):325-333. doi:10.3109/09638288.2012.705220

11. Trøstrup J, Andersen H, Kam CAM, et al. Assessment of mobility in older people hospitalized for medical illness using the de Morton Mobility Index and cumulated ambulation score-validity and minimal clinical important difference. J Geriatr Phys Ther. 2019;42(3):153-160. doi:10.1519/JPT.0000000000000170

12. Gazzoti A, Meyer U, Freystaetter G, et al. Physical performance among patients aged 70+ in acute care: a preliminary comparison between the Short Physical Performance Battery and the De Morton Mobility Index with regard to sensitivity to change and prediction of discharge destination. Aging Clin Exp Res. 2020;32(4):579-586. doi:10.1007/s40520-019-1249-9

13. Tavares LS, Moreno NA, de Aquino BG, et al. Reliability, validity, interpretability and responsiveness of the DEMMl mobility index for Brazilian older hospitalized patients. PLoS One. 2020;15(3):e0230047. doi:10.1371/journal.pone.0230047

14. Braun T, Schulz R-J, Reinke J. Reliability and validity of the German translation of the de Morton Mobility Index performed by physiotherapists in patients admitted to a sub-acute inpatient geriatric rehabilitation hospital. BMC Geriatr. 2015;15:38. doi:10.1186/ s12877-015-0035-y

15. Søndergaard K, Petersen LE, Pedersen MK, et al. The responsiveness and predictive validity of the de Morton Mobility Index in geriatric rehabilitation. Disabil Rehabil. 2020 Jun 12. [Epub ahead of print] doi:10.1080/09638288.2020.1771438

16. de Morton NA, Brusco NK, Wood L, et al. The de Morton Mobility Index (DEMMI) provides a valid method for measuring and monitoring the mobility of patients making the transition from hospital to the 
community: an observational study. J Physiother. 2011;57(2):109116. doi:10.1016/S1836-9553(11)70021-2

17. Caronni A, Sterpi I, Antoniotti P, et al. Criterion validity of the instrumented Timed Up and Go test: a partial least square regression study. Gait Posture. 2018;61(3):287-293. doi:10.1016/j.gaitpost.2018.01.015

18. Kristensen MT, Bloch ML, Jonsson LR, Jakobsen TL. Interrater reliability of the standardized Timed Up and Go Test when used in hospitalized and community-dwelling individuals. Physiother Res Int. 2019;24(2):e1769. doi:10.1002/pri.1769

19. Yuksel E, Kalkan S, Cekmece S, et al. Assessing minimal detectable changes and test-retest reliability of the timed up and go test and 2-minute walk test in patients with total knee arthroplasty. $J$ Arthroplasty. 2017;32(2):426-430. doi:10.1016/j.arth.2016.07.031

20. Yuksel E, Unver B, Kalkan S, Karatosun V. Reliability and minimal detectable change of the 2-minute walk test and Timed Up and Go test in patients with total hip arthroplasty. Hip Int. 2021;31(1):43-49. doi:10.1177/1120700019888614

21. Faleide AGH, Bogen BE, Magnussen LH. Intra-session test-retest reliability of the Timed "Up \& Go" Test when performed by patients with hip fractures. Eur J Physiother. 2015;17(2):89-97. doi:10.3109/21679169.2015.1043579

22. Barry E, Galvin R, Keogh C, et al. Is the timed up and go test a useful predictor of risk of falls in community dwelling older adults: a systematic review and meta- analysis. BMC Geriatr. 2014;14:14. doi:10.1186/1471-2318-14-14

23. Kojima G, Masud T, Kendrick D, et al. Does the timed up and go test predict future falls among British community-dwelling older people? Prospective cohort study nested within a randomised controlled trial. BMC Geriatr. 2015;15:38. doi:10.1186/s12877-015-0039-7

24. Shumway-Cook A, Brauer S, Woollacott M. Predicting the probability for falls in community-dwelling older adults using the timed up \& go test. Phys Ther. 2000;80(9):896-903.

25. Jeong SM, Shin DW, Han K, et al. Timed Up-and-Go test is a useful predictor of fracture incidence. Bone. 2019;127:474-481. doi:10.1016/j.bone.2019.07.018

26. Donaghue OA, Savva GM, Börsch-Supan A, Kenny RA. Reliability, measurement error and minimum detectable change in reliability measurement error and minimum detectable change in mobility measures: a cohort study of community dwelling adults aged 50 years and over in Ireland. BMJ Open. 2019;9(11):e030475. doi:10/1136.bmjopen-2019-030475

27. Freter SH, Fruchter N. Relationship between timed 'up and go' and gait time in an elderly orthopaedic rehabilitation population. Clin Rehabil. 2000;14(1):96-101. doi:10.1191/026921500675545616

28. Kear BM, Guck TP, McGaha AL. Timed up and go (TUG) test: normative reference values for ages 20 to 59 years and relationships with physical and mental health risk factors. J Prim Care Community Health. 2017;8(1):9-13. doi:10.1177/2150131916659282

29. Abellan van Kan G, Rolland Y, Andrieu S, et al. Gait speed at usual pace as a predictor of adverse outcomes in community-dwelling older people: an International Academy on Nutrition and Aging (IANA) Task Force. J Nutr Health Aging. 2009;13(10)881-889. doi:10.1007/s12603-009-0246-z

30. Unver B, Baris $\mathrm{RH}$, Yusel E, et al. Reliability of 4-meter and 10-meter walk tests after lower extremity surgery. Disabil Rehabil. 2017;39(25):2572-2576. doi:10.1080/09638288.2016.1236153

31. Fritz S, Lusardi M. White paper: "walking speed: the sixth vital sign." J Geriatr Phys Ther. 2009;32(2):46-49.

32. Studenski $S$, Perera S, Patel K, et al. Gait speed and survival in older adults. JAMA. 2011;305(1):50-58. doi:10.1001/jama.2010.1923
33. Bohannon R. Comfortable and maximum walking speed of adults aged 20-79 years: reference values and determinants. Age Ageing. 1997;26(1):15-19. doi:10.1093/ageing/26.1.15

34. Perera S, Mody SH, Woodman RC, Studenski SA. Meaningful change and responsiveness in common physical performance in older adults. J Am Geriatr Soc. 2006;54(5):743-749. doi:10.1111/j.1532-5415.2006.00701.x

35. Hollman J, Beckman B, Brandt R, et al. Minimum detectable change in gait velocity during acute rehabilitation following hip fracture. J Geriatr Phys Ther. 2008;31(2):53-56. doi:10.1519/00139143-200831020-00003

36. Bohannon RW, Andrews AW. Normal walking speed: a descriptive meta-analysis. Physiotherapy. 2011;97(3):182-189. doi:10.1016/j.physio.2010.12.004

37. Granger CV, Hamilton BB, Keith RA, et al. Advances in functional assessment for medical rehabilitation. Top Geriatr Rehabil. 1986;1:59-74.

38. Keith RA, Granger CV, Hamilton BB, Sherwin FS. The Functional Independence Measure: a new tool for rehabilitation. In: Eisenberg MG, Grzesiak RC, eds. Advances in Clinical Rehabilitation. Springer-Verlag; 1987:6-18.

39. Linacre JM, Heinemann AW, Wright BD, et al. The structure and stability of the Functional Independence Measure. Arch Phys Med Rehabil. 1994;75(2):127-132.

40. Coster WJ, Haley SM, Jette AM. Measuring patient-reported outcomes after discharge from inpatient rehabilitation settings. $J$ Rehabil Med. 2006;38(4):237-242. doi:10.1080/16501970600609774

41. Street L. Frequently asked questions about FIM. Journal of the Australasian Rehabilitation Nurses Association. 2014;17(1):21-22. https://ro.uow.edu.au/ahsri/296/

42. Green JP, Gordon R, Blanchard MB, et al. Development of the Australian National Subacute and Non-acute Patient (AN-SNAP) Classification. Version 4 Final Report. Australian Health Services Research Institute, University of Wollongong, 2015. https://ro.uow. edu.au/ahsri/760

43. Australasian Rehabilitation Outcomes Centre. University of Wollongong, Australia. https://www.uow.edu.au/ahsri/aroc/

44. Green J, Gordon R, Kobel C, et al; Centre for Health Service Development. The Australian National Subacute and Non-acute Patient Classification. AN-SNAP V4 User Manual. May 2015. https://documents.uow.edu.au/content/groups/public/@web/@ chsd/@aroc/documents/doc/uow194637.pdf

45. Alexander TL, Simmonds FD, Capelle JT, Green LJ. Anywhere Hospital AROC Impairment Specific Report on Reconditioning (Inpatient-Pathway 3), July 2018-June 2019. Australasian Rehabilitation Outcomes Centre, Australian Health Services Research Institute, University of Wollongong; 2019. ro.uow.edu.au/ ahsri/1110

46. Evans JD. Straightforward Statistics for the Behavioural Sciences. Brooks/Cole Publishing; 1996.

47. Lee SP, Dufek J, Hickman R, Schuerman S. Influence of procedural factors on the reliability and performance of the timed up-and-go test in older adults. Int J Gerontol. 2016;10(1):37-42. doi:10.1016/j.jige.2015

48. New PW, Scroggie GD, Williams CM. The validity, reliability, responsiveness and minimal clinically important difference of the de Morton Mobility Index in rehabilitation. Disabil Rehabil. 2017;39(10):10391043. doi:10.10801/09638288.2016.1179800

49. Nakaguchi T, Ishimoto $\mathrm{Y}$, Akazawa N. Functional Independence Measure for patients with locomotor disorders in convalescent rehabilitation wards. Clinically significant minimum difference in exercise score gain. Physiotherapy Science. 2018;33(2):235-240. 

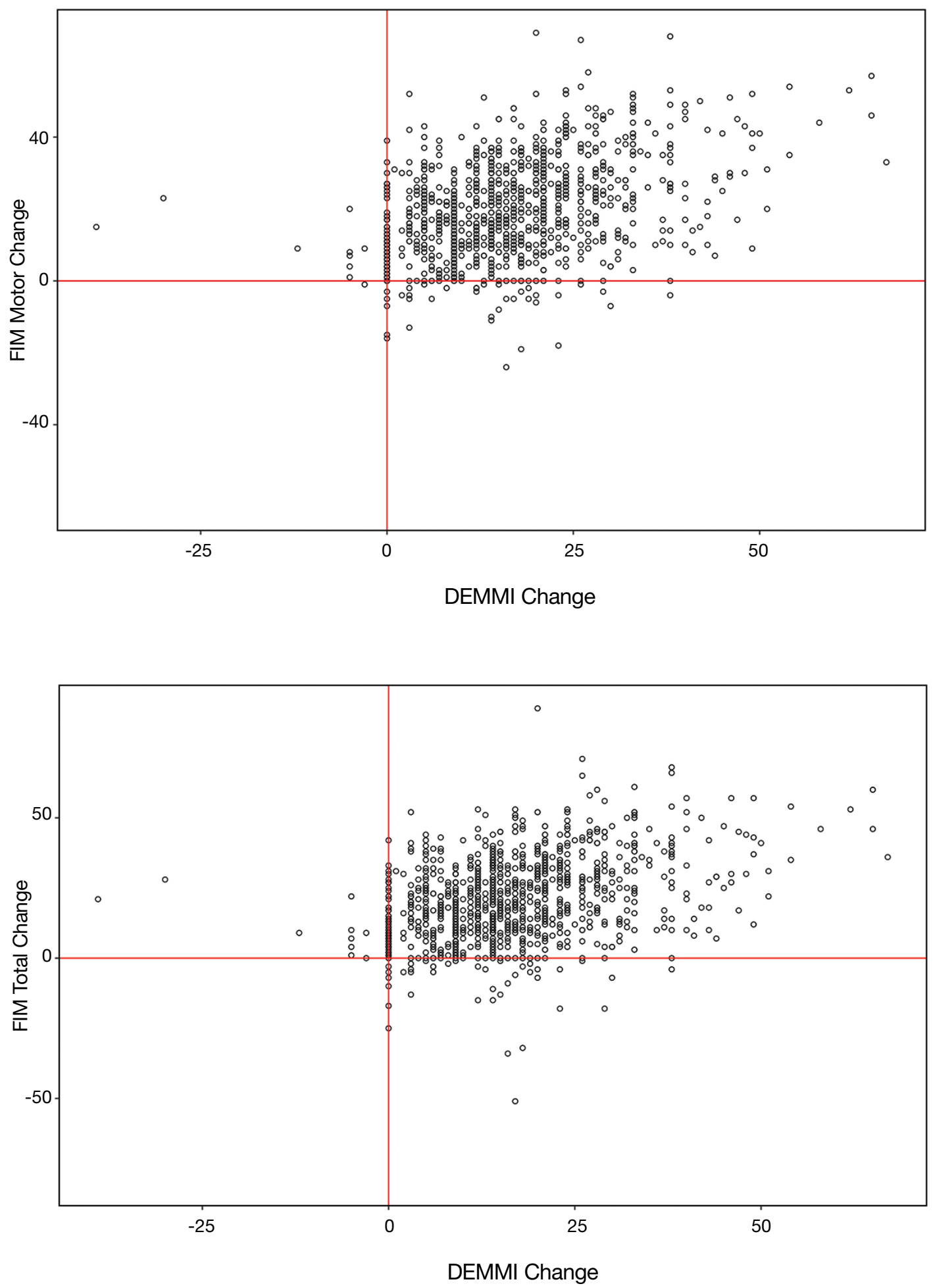

Figure. Correlation Between Change Scores (DEMMI, TUG, 10MWT [m/s], and FIM Motor, FIM Total). 

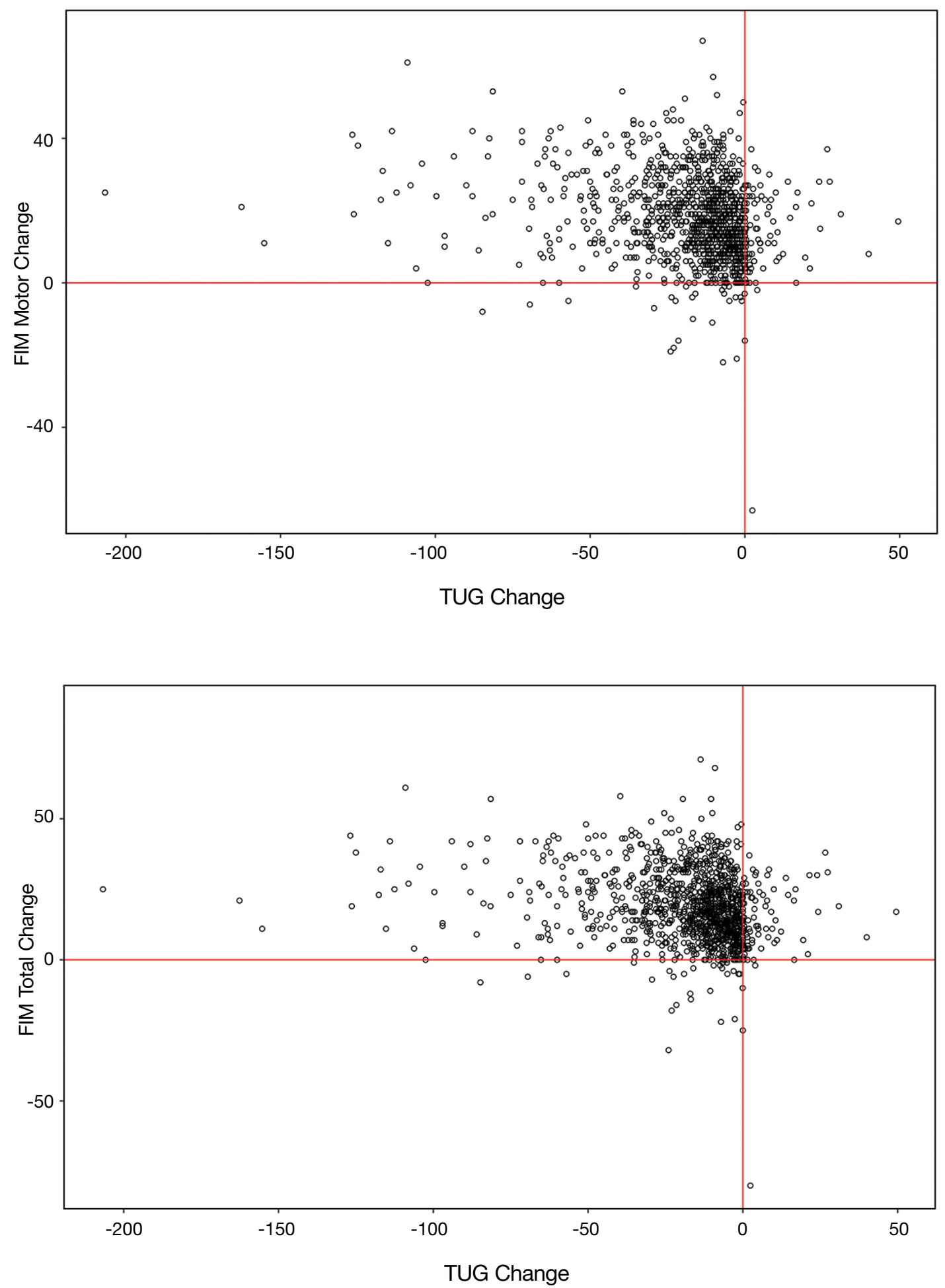

Figure. Correlation Between Change Scores (DEMMI, TUG, 10MWT [m/s], and FIM Motor, FIM Total). continued 

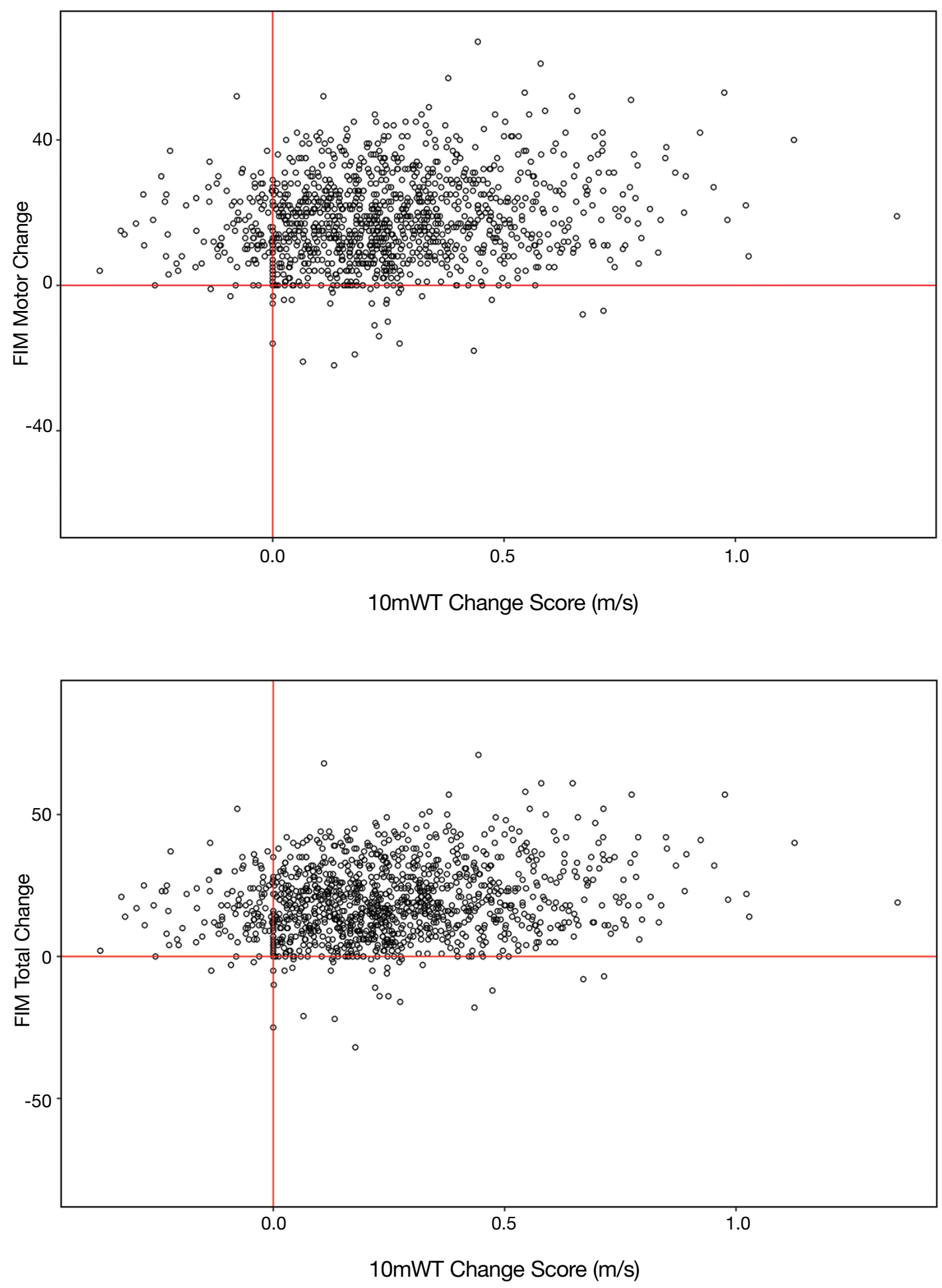

Figure. Correlation Between Change Scores (DEMMI, TUG, 10MWT [m/s], and FIM Motor, FIM Total). continued 


\begin{tabular}{|c|c|c|c|}
\hline & $\begin{array}{c}\text { Item } \\
\text { No }\end{array}$ & Recommendation & \\
\hline \multirow[t]{2}{*}{ Title and abstract } & 1 & $\begin{array}{l}\text { (a) Indicate the study's design with a commonly used term in the title or the } \\
\text { abstract }\end{array}$ & $\nabla$ \\
\hline & & $\begin{array}{l}\text { (b) Provide in the abstract an informative and balanced summary of what was } \\
\text { done and what was found }\end{array}$ & $\square$ \\
\hline \multicolumn{4}{|l|}{ Introduction } \\
\hline Background/rationale & 2 & $\begin{array}{l}\text { Explain the scientific background and rationale for the investigation being } \\
\text { reported }\end{array}$ & $\square$ \\
\hline Objectives & 3 & State specific objectives, including any prespecified hypotheses & $\nabla$ \\
\hline \multicolumn{4}{|l|}{ Methods } \\
\hline Study design & 4 & Present key elements of study design early in the paper & $\square$ \\
\hline Setting & 5 & $\begin{array}{l}\text { Describe the setting, locations, and relevant dates, including periods of } \\
\text { recruitment, exposure, follow-up, and data collection }\end{array}$ & $\square$ \\
\hline Participants & 6 & $\begin{array}{l}\text { (a) Cohort study - Give the eligibility criteria, and the sources and methods } \\
\text { of selection of participants. Describe methods of follow-up } \\
\text { Case-control study - Give the eligibility criteria, and the sources and } \\
\text { methods of case ascertainment and control selection. Give the rationale for } \\
\text { the choice of cases and controls } \\
\text { Cross-sectional study - Give the eligibility criteria, and the sources and } \\
\text { methods of selection of participants }\end{array}$ & $\nabla$ \\
\hline
\end{tabular}

(b) Cohort study —For matched studies, give matching criteria and number of exposed and unexposed

Case-control study—For matched studies, give matching criteria and the number of controls per case

\begin{tabular}{|c|c|c|c|}
\hline Variables & 7 & $\begin{array}{l}\text { Clearly define all outcomes, exposures, predictors, potential confounders, and } \\
\text { effect modifiers. Give diagnostic criteria, if applicable }\end{array}$ & $\square$ \\
\hline $\begin{array}{l}\text { Data sources/ } \\
\text { measurement }\end{array}$ & $8^{*}$ & $\begin{array}{l}\text { For each variable of interest, give sources of data and details of methods of } \\
\text { assessment (measurement). Describe comparability of assessment methods if } \\
\text { there is more than one group }\end{array}$ & $\square$ \\
\hline Bias & 9 & Describe any efforts to address potential sources of bias & $\square$ \\
\hline Study size & 10 & Explain how the study size was arrived at & $\nabla$ \\
\hline Quantitative variables & 11 & $\begin{array}{l}\text { Explain how quantitative variables were handled in the analyses. If } \\
\text { applicable, describe which groupings were chosen and why }\end{array}$ & $\square$ \\
\hline \multirow[t]{4}{*}{ Statistical methods } & \multirow[t]{4}{*}{12} & $\begin{array}{l}\text { (a) Describe all statistical methods, including those used to control for } \\
\text { confounding }\end{array}$ & $\nabla$ \\
\hline & & (b) Describe any methods used to examine subgroups and interactions & $\nabla$ \\
\hline & & (c) Explain how missing data were addressed & $\square$ \\
\hline & & $\begin{array}{l}\text { (d) Cohort study-If applicable, explain how loss to follow-up was addressed } \\
\text { Case-control study —-If applicable, explain how matching of cases and } \\
\text { controls was addressed } \\
\text { Cross-sectional study —-If applicable, describe analytical methods taking } \\
\text { account of sampling strategy }\end{array}$ & N/A \\
\hline
\end{tabular}

(e) Describe any sensitivity analyses 


\section{Results}

\begin{tabular}{|c|c|c|c|}
\hline \multirow[t]{3}{*}{ Participants } & $13 *$ & $\begin{array}{l}\text { (a) Report numbers of individuals at each stage of study-eg numbers potentially } \\
\text { eligible, examined for eligibility, confirmed eligible, included in the study, completing } \\
\text { follow-up, and analysed }\end{array}$ & $\square$ \\
\hline & & (b) Give reasons for non-participation at each stage & $\mathrm{N} / \mathrm{A}$ \\
\hline & & (c) Consider use of a flow diagram & $\mathrm{N} / \mathrm{A}$ \\
\hline \multirow[t]{3}{*}{$\begin{array}{l}\text { Descriptive } \\
\text { data }\end{array}$} & $14^{*}$ & $\begin{array}{l}\text { (a) Give characteristics of study participants (eg demographic, clinical, social) and } \\
\text { information on exposures and potential confounders }\end{array}$ & $\square$ \\
\hline & & (b) Indicate number of participants with missing data for each variable of interest & $\square$ \\
\hline & & (c) Cohort study-Summarise follow-up time (eg, average and total amount) & $\square$ \\
\hline \multirow[t]{2}{*}{ Outcome data } & $15^{*}$ & Cohort study-Report numbers of outcome events or summary measures over time & $\nabla$ \\
\hline & & $\begin{array}{l}\text { Case-control study-Report numbers in each exposure category, or summary measures } \\
\text { of exposure }\end{array}$ & \\
\hline
\end{tabular}

\begin{tabular}{|c|c|c|c|}
\hline \multirow[t]{3}{*}{ Main results } & 16 & $\begin{array}{l}\text { (a) Give unadjusted estimates and, if applicable, confounder-adjusted estimates and } \\
\text { their precision (eg, } 95 \% \text { confidence interval). Make clear which confounders were } \\
\text { adjusted for and why they were included }\end{array}$ & $\square$ \\
\hline & & (b) Report category boundaries when continuous variables were categorized & $\square$ \\
\hline & & $\begin{array}{l}\text { (c) If relevant, consider translating estimates of relative risk into absolute risk for a } \\
\text { meaningful time period }\end{array}$ & N/A \\
\hline Other analyses & 17 & $\begin{array}{l}\text { Report other analyses done-eg analyses of subgroups and interactions, and sensitivity } \\
\text { analyses }\end{array}$ & $\square$ \\
\hline \multicolumn{4}{|l|}{ Discussion } \\
\hline Key results & 18 & Summarise key results with reference to study objectives & $\nabla$ \\
\hline Limitations & 19 & $\begin{array}{l}\text { Discuss limitations of the study, taking into account sources of potential bias or } \\
\text { imprecision. Discuss both direction and magnitude of any potential bias }\end{array}$ & $\nabla$ \\
\hline Interpretation & 20 & $\begin{array}{l}\text { Give a cautious overall interpretation of results considering objectives, limitations, } \\
\text { multiplicity of analyses, results from similar studies, and other relevant evidence }\end{array}$ & $\square$ \\
\hline Generalisability & 21 & Discuss the generalisability (external validity) of the study results & $\nabla$ \\
\hline
\end{tabular}

Other information

Funding 22 Give the source of funding and the role of the funders for the present study and, if $\square$ applicable, for the original study on which the present article is based

*Give information separately for cases and controls in case-control studies and, if applicable, for exposed and unexposed groups in cohort and cross-sectional studies.

Note: An Explanation and Elaboration article discusses each checklist item and gives methodological background and published examples of transparent reporting. The STROBE checklist is best used in conjunction with this article (freely available on the Web sites of PLoS Medicine at http://www.plosmedicine.org/, Annals of Internal Medicine at http://www.annals.org/, and Epidemiology at http://www.epidem.com/). Information on the STROBE Initiative is available at www.strobe-statement.org. 